\title{
Type-2 Fuzzy Modeling for Acoustic Emission Signal in Precision Manufacturing
}

\author{
Qun Ren, Luc Baron, and Marek Balazinski \\ Department of Mechanical Engineering, Ecole Polytechnique de Montreal, CP 6079, Succursale Centre-Ville, \\ Montreal, QC, Canada H3C $3 A 7$ \\ Correspondence should be addressed to Qun Ren, qun.ren@polymtl.ca
}

Received 17 March 2011; Revised 6 June 2011; Accepted 20 June 2011

Academic Editor: Andrzej Dzielinski

Copyright ( 92011 Qun Ren et al. This is an open access article distributed under the Creative Commons Attribution License, which permits unrestricted use, distribution, and reproduction in any medium, provided the original work is properly cited.

This paper presents an application of type-2 fuzzy logic on acoustic emission (AE) signal modeling in precision manufacturing. Type-2 fuzzy modeling is used to identify the AE signal in precision machining. It provides a simple way to arrive at a definite conclusion without understanding the exact physics of the machining process. Moreover, the interval set of the output from the type-2 fuzzy approach assesses the information about the uncertainty in the AE signal, which can be of great value for investigation of tool wear conditions. Experiments show that the development of the AE signal uncertainty trend corresponds to that of the tool wear. Information from the AE uncertainty scheme can be used to make decisions or investigate the tool condition so as to enhance the reliability of tool wear.

\section{Introduction}

Related to advances in machine tools, manufacturing systems and material technology, machining practice is changing from conventional machining to precision machining, even high-precision machining. The scale of precision machining becomes finer and closer to the dimensional scale of material properties. As a result, the acoustic emission (AE) from microscopic sources becomes significant [1].

$\mathrm{AE}$ is the class of phenomena whereby transient elastic waves are generated by the rapid release of energy by a localized source or sources within a material, or transient elastic wave(s) so generated (ANSI/ASTM E 610-89). Emissions from process changes, like tool wear, chip formation, can be directly related to the mechanics of the process. AE-based sensing methodologies for tool condition and cutting process monitoring have been studied since 1977 [2]. Signal processing schemes were used to treat AE signal to extract the most useful information, for example, time series analysis [3, 4], Fourier transform [5, 6], Gabor transform [7-9], and wavelet transform [10-13], and so forth. Because the information obtained during the machining process is vague, incomplete or imprecise, these conventional methods need a large number of cutting experiments and additional assumptions in many circumstances for effective uncertainty handling. These requirements reduce the reliability of the models and increase money and time consumption. Moreover, the general mathematical relation cannot be used to map the nonlinear relationship between the AE signal and tool wear condition [14]. Artificial intelligence methods have played an important role in modern tool condition monitoring (TCM) to observe the relation between tool wear and AE signal such as neural networks [15, 16], fuzzy logic [17], and fuzzy neural network [18-22]. The increased use of artificial intelligence within TCM has enabled the development of more robust and comprehensive strategies.

It is believed that a relatively uncontaminated AE signal can be obtained because AE frequency range is much higher than that of machine vibrations and environmental noises and does not interfere with the cutting operation. AE can be effectively used for TCM applications at the precision scale. In fact, it is impossible to get an accurate AE signal. It is because that machining process varies considerably depending on the part material, temperature, cutting fluids, chip formation, the tool material, temperature, chatter and vibration, and so forth. Additionally, AE sensors are very sensitive to environmental changes such as changes in temperature, 
humidity, circuit noise, and even the locating error of the sensors. Moreover, changes of cutting conditions also affect the behaviour of acoustic emission signals. None of previous studies considered the uncertainty in AE signal.

The aim of this paper is to present an innovative type- 2 Takagi-Sugeno-Kang (TSK) fuzzy modeling to capture the uncertainties in the $\mathrm{AE}$ signal in machining process in order to overcome the challenges in TCM. Type-2 TSK fuzzy modeling method is not only a powerful tool to model high complex nonlinear physical processes, but also a great estimator for the ambiguities and uncertainties associated with the system. It is capable to arrive at a definite conclusion without understanding the exact physics of the machining process. In this paper, type-2 TSK fuzzy modeling is implemented to filter the raw AE signal directly from the AE sensor during turning process. Furthermore, its output interval set assesses the uncertainty information in $\mathrm{AE}$, which is of great value to a decision maker and can be used to investigate the complicated tool wear condition during machining process.

This paper is divided into four sections. Section 1 gives a brief overview of previous studies on AE-based TCM. Section 2 introduces TSK fuzzy logic and the type-2 TSK fuzzy modeling algorithm. Section 3 presents a case study where type-2 TSK fuzzy approach is used to filter the raw $\mathrm{AE}$ signal directly from the $\mathrm{AE}$ sensor and identify the uncertainty interval of $\mathrm{AE}$. The experimental results show the effectiveness and advantages of type-2 TSK fuzzy modeling. Conclusion is given in Section 4.

\section{Type-2 TSK Fuzzy Uncertainty Modeling}

2.1. TSK Fuzzy Logic. Fuzzy logic has been originally proposed by Zadeh in his famous paper "Fuzzy Sets" in 1965 [23]. Fuzzy logic provides a simple way to obtain a definite conclusion based upon vague, ambiguous, imprecise, noisy, or missing input information. TSK fuzzy logic system (FLS) $[24,25]$ was proposed in an effort to develop a systematic approach to generate fuzzy rules from a given input-output data set. This model consists of rules with fuzzy antecedents and a mathematical function in the consequent part. The antecedents divide the input space into a set of fuzzy regions, while consequents describe behaviour of the system in those regions. TSK FLS has a powerful capability of explaining complex relations among variables using rule consequents which are functions of the input variables. This is due to the model's properties: on one hand being a general non-linear approximator that can approximate every continuous mapping and on the other hand being a piecewise linear model that is relatively easy to interpret [26] and whose linear submodels can be exploited for control and fault detection [27].

A generalized type-1 TSK model can be described by fuzzy IF-THEN rules which represent input-output relations of the system. For a MISO first-order type-1 TSK model, its $k$ th rule can be expressed as

$$
\text { IF } x_{1} \text { is } Q_{1 k}, x_{2} \text { is } Q_{2 k}, \ldots, x_{n} \text { is } Q_{n k} \text {, }
$$

THEN $Z$ is $w^{k}=p_{0}^{k}+p_{1}^{k} x_{1}+p_{2}^{k} x_{2}+\cdots+p_{n}^{k} x_{n}$, where $x_{1}, x_{2} \ldots, x_{n}$ and $Z$ are linguistic variables; $Q_{1 k}, Q_{2 k}, \ldots$, and $Q_{n k}$ are the fuzzy sets on universe of discourses $U, V, \ldots$, and $W$, and $p_{0}^{k}, p_{1}^{k}, \ldots$, and $p_{n}^{k}$ are regression parameters.

A Gaussian MF can be expressed by the following formula for the $v$ th variable:

$$
Q_{v}^{k}=\exp \left[-\frac{1}{2}\left(\frac{x_{v}-x_{v}^{k *}}{\sigma}\right)^{2}\right]
$$

where $x_{v}^{k *}$ is the mean of the $v$ th input feature in the $k$ th rule for $v \in[0, n] \cdot \sigma$ is the standard deviation of Gaussian MF.

Based on Zadeh's concept of type-2 fuzzy sets and extension principle [28], practical algorithms for conjunction, disjunction, and complement operations of type-2 fuzzy sets are obtained by extending previous studies [29]. Prior work [30] also introduced embedded interval-valued type-2 fuzzy sets and developed a general formula for the extended composition of type- 2 relations, which is considered as an extension of the type- 1 composition. The characterization in the definition of type-2 fuzzy sets uses the notion that type-1 fuzzy sets can be thought of as a first-order approximation of uncertainty and, therefore, type-2 fuzzy sets provide a second-order approximation. They play an important role in modeling uncertainties that exist in fuzzy logic systems [31] and are becoming increasingly important in the goal of "Computing with Words" [32] and "Computational Theory of Perceptions" [33]. A complete type-2 fuzzy logic theory with the handling of uncertainties was also established [34]. Because of its larger number of design parameters for each rule, it was believed that type-2 FLS have the potential to be used in control [35] and other areas where a type-1 model may be unable to perform well [36]. Type-2 TSK FLS and its structures were presented in 1999 [37].

An example of a type- $2 \mathrm{MF}$, whose vertices have been assumed to vary over some interval of value, is depicted in Figure 1. The footprint of uncertainty (FOU) associated with this type-2 MF is a bounded shaded region. FOU represents the entire interval type-2 fuzzy set $\widetilde{Q}$. Upper MF and Lower MF are two type-1 MFs that are bounds for the FOU of a type-2 set $\widetilde{Q}$. The intersections of crisp input $x^{0}$ show that there are lower MF degree $u$ and upper MF degree $\bar{u}$ with respective lower and upper MFs. Detailed type-2 fuzzy sets and interval type-2 FLS background material can be found in [38].

A generalized $k$ th rule in the first-order type-2 TSK fuzzy MISO system can be expressed as

$$
\begin{gathered}
\text { IF } x_{1} \text { is } \widetilde{Q}_{1 k}, x_{2} \text { is } \widetilde{Q}_{2 k}, \ldots, x_{n} \text { is } \widetilde{Q}_{n k}, \\
\text { THEN } Z \text { is } \widetilde{w}^{k}=\tilde{p}_{0}^{k}+\widetilde{p}_{1}^{k} x_{1}+\widetilde{p}_{2}^{k} x_{2}+\cdots+\widetilde{p}_{n}^{k} x_{n},
\end{gathered}
$$

where $\tilde{p}_{0}^{k}, \tilde{p}_{1}^{k}, \ldots, \tilde{p}_{n}^{k}$ are consequent parameters, $\widetilde{w}^{k}$ is the output from the $k$ th IF-THEN rule in an $M$-rule FLS, $\widetilde{Q}_{1 k}, \widetilde{Q}_{2 k}, \ldots, \widetilde{Q}_{n k}$ are fuzzy sets on the universe of discourse.

One way to obtain a type-2 model directly form a type-1 model is by extending the cluster center, $x_{j k}^{*}$, from a point to 


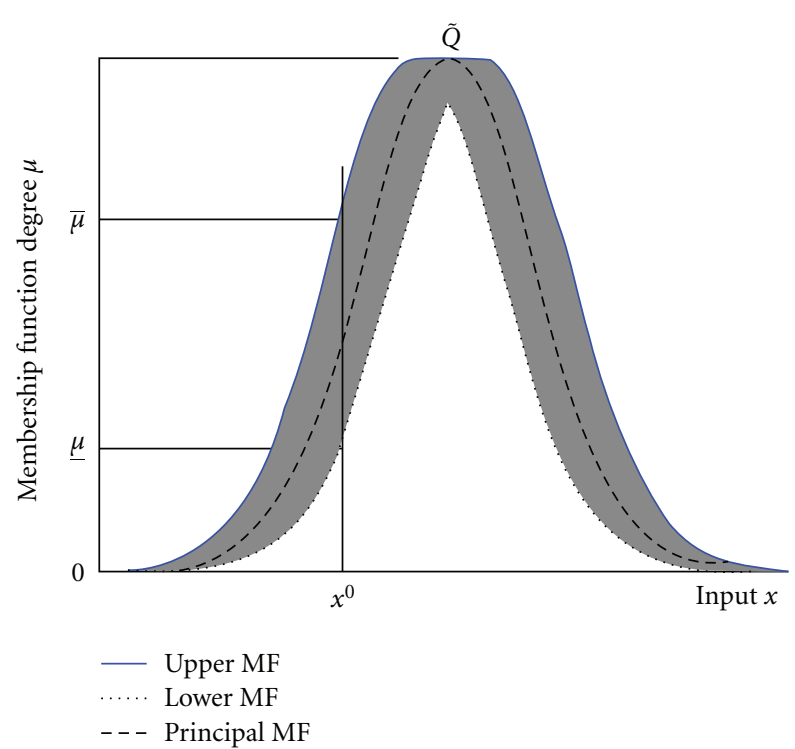

FIgURE 1: Type-2 Gaussian MF.

a constant-width interval-valued fuzzy set, $\tilde{x}_{j k}^{*}$ as shown in Figure 2. The size of the interval is $2 \mathrm{a}$ :

$$
\tilde{x}_{j k}^{*}=\left[x_{j k}^{*}\left(1-a_{j}^{k}\right), x_{j k}^{*}\left(1+a_{j}^{k}\right)\right] .
$$

Consequent parameter $\tilde{p}_{j}^{k}$ is obtained by extending the consequent parameter $p_{j}^{k}$ from its type- 1 counterpart using the following expression:

$$
\tilde{p}_{j}^{k}=\left[p_{j}^{k}-s_{j}^{k}, p_{j}^{k}+s_{j}^{k}\right],
$$

where $j \in[0, n]$, and $s_{j}^{k}$ denotes the spread of fuzzy numbers $\tilde{p}_{j}^{k}$.

Hence, the premise MF is changed from type- 1 fuzzy set into type-2 fuzzy set, that is,

$$
\widetilde{Q}_{j k}=\exp \left[-\frac{1}{2}\left(\frac{x_{j}-x_{j k}^{*}\left(1 \pm a_{j}^{k}\right)}{\sigma_{j}^{k}}\right)^{2}\right],
$$

where $\sigma_{j}^{k}$ is the standard deviation of Gaussian MF.

Type-2 FLSs are very useful in circumstances in which it is difficult to determine an exact membership function for a fuzzy set. They can be used to handle rule uncertainties and even measurement uncertainties. Type-2 FLSs moves the world of FLSs into a fundamentally new and important direction. To date, type- $2 \mathrm{FL}$ moves in progressive ways where type-1 FL is eventually replaced or supplemented by type- 2 FL [39].

2.2. Type-2 Fuzzy Modelling Algorithm. The diagram of type-2 TSK fuzzy modelling algorithm is shown in Figure 3. This algorithm is initially presented in [40]. Type- 2 TSK fuzzy approach includes two steps: the first step is type-1 fuzzy modelling to eliminate noise components in the $\mathrm{AE}$ signal and the second consists of expanding the type-1 fuzzy

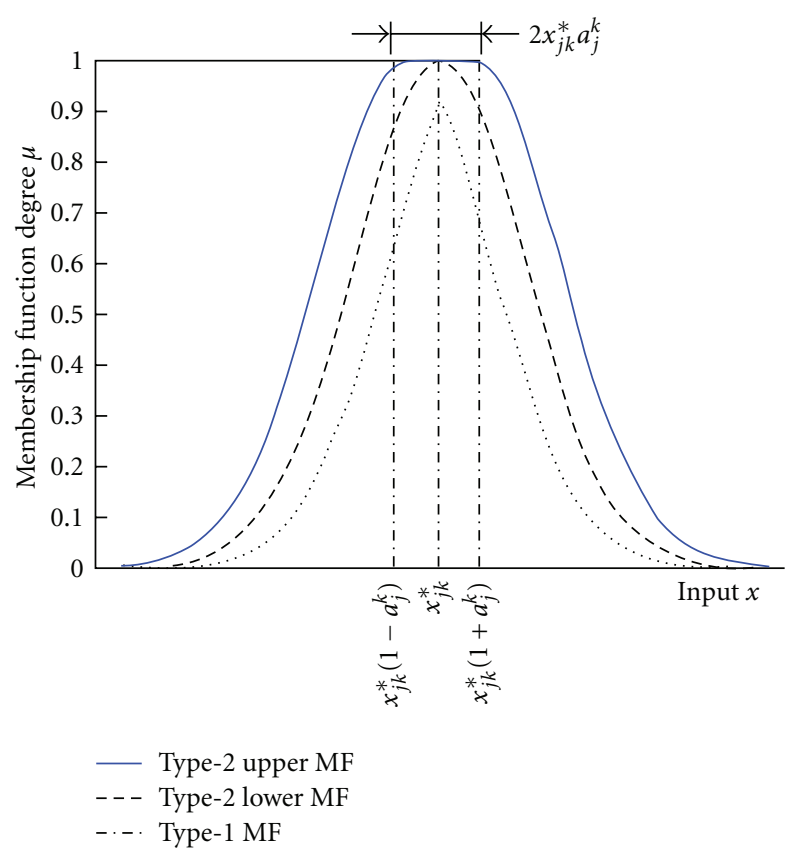

Figure 2: Spread of cluster center.

system to its type- 2 counterpart to obtain the information of uncertainty in AE signal. The first step is type-1 TSK fuzzy approach. Subtractive clustering method [41] (see Appendix A) combined with a least-square estimation algorithm is used to cope with the nonlinearity of the $\mathrm{AE}$ and the uncertainty of imprecise data from measurement. A detailed description for this type-1 fuzzy modelling can be found in $[42,43]$. The second step is type-2 TSK fuzzy approach. The type-1 MFs are considered as the principal MFs of a type-2 FLS, the antecedent MFs are extended as interval type-2 fuzzy memberships by assigning uncertainty to cluster centers using (4), and the consequent parameters are extended as fuzzy numbers by assigning uncertainty to consequent parameter values using (5). The type-2 TSK fuzzy inference engine is presented in Appendix B. Through enumerative search of optimum values of spreading percentage of cluster centers and consequent parameters, the best approach for analysing AE signal is obtained. The Detailed description for this modelling algorithm can be found in [44]. Examples of application of this algorithm can be found in [45-47].

Compared with traditional methods and its type- 1 counterpart, type-2 fuzzy modeling can not only obtain a modeling result directly from the input-output data sets, but it can also capture the uncertainty interval of the result $[34,48]$. The information about uncertainties in the type-2 interval output is very helpful for decision making.

\section{Experimental Study}

3.1. Experimental Setup. The experiment described in this paper was taken on the BOEHRINGER CNC lathe. The workpiece material was Titanium Metal matrix Composite (Ti MMC) 10\% wt. TiC/Ti-6Al-4V where the microstructural response of cast Ti-6Al-4V-based composite contains 


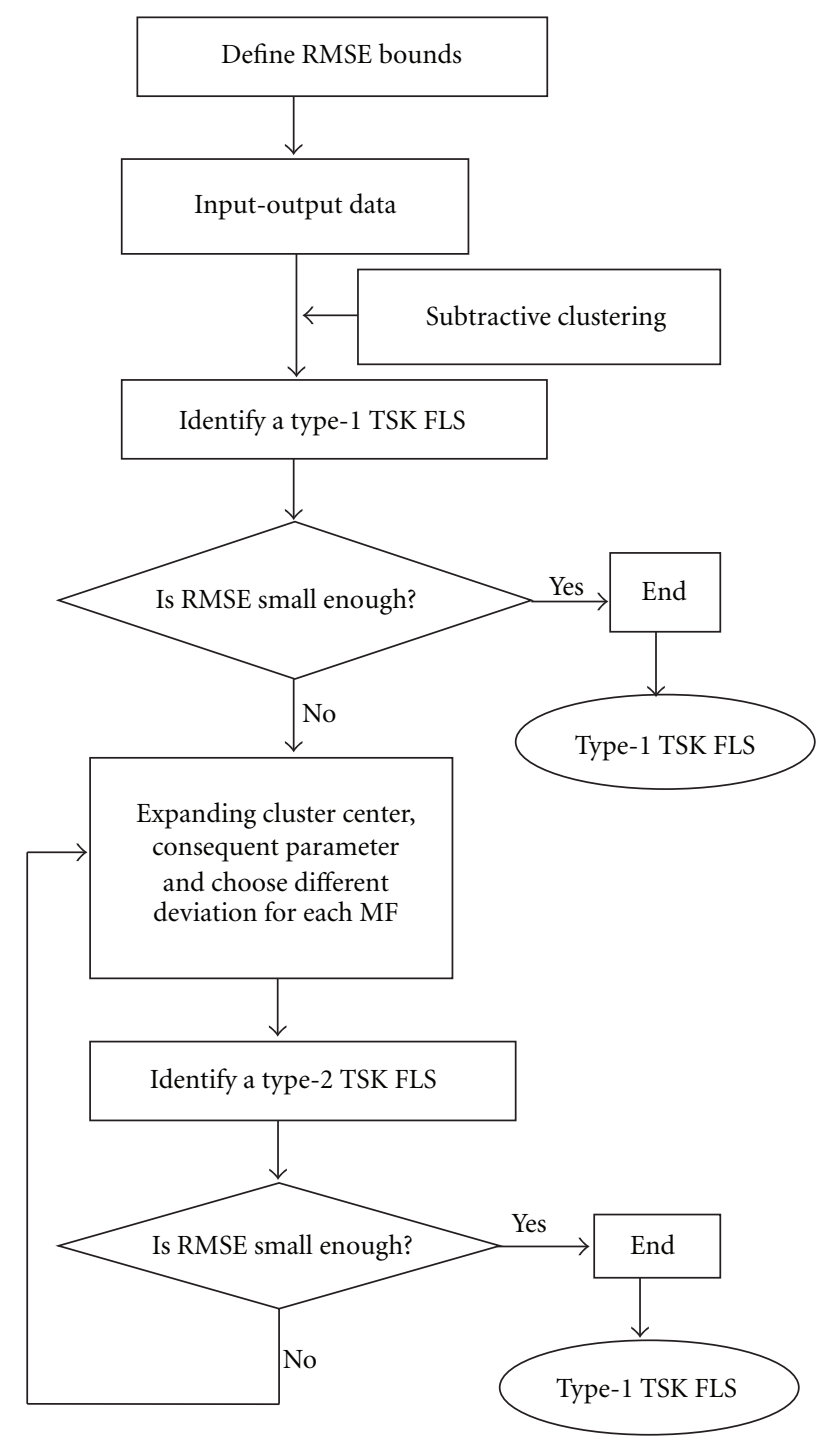

Figure 3: Diagram of subtractive clustering-based type-2 TSK fuzzy approach.

10 vol.- $\%$ TiC reinforcement. This kind of material is widely used in aerospace and military applications for its high hardness, light weight, high bending strength, fracture toughness, higher modulus, and elevated temperature resistance and high wear resistance. Consequently, its machining is very difficult.

The cutting tool insert was carbide from SECO tools (CNMG 120408 MF1 CP200). Turning test was done on a cylinder of Ti MMC 2.5" diameter in dry machining conditions. The machining speed was chosen to exceed the manufacturer's recommendation in order to see and check the tool cutting speed limits $(80 \mathrm{~m} / \mathrm{min})$. The cutting depth was kept at $0.15 \mathrm{~mm}$ and the cutting feed was $0.1 \mathrm{~mm}$.

The aim of this study was to find out the relation between $\mathrm{AE}$ and tool wear. During the test, every time when cutting length reached $10 \mathrm{~mm}$, the machine was stopped to manually measure the tool wear parameter $\left(V B_{B}\right)$. Figure 4 shows one example of a raw $\mathrm{AE}$ signal $\mathrm{AE}_{\text {raw }}$ directly from $\mathrm{AE}$ sensor. During the first $5 \sim 8 \mathrm{~s}$, the cutting tool is approaching

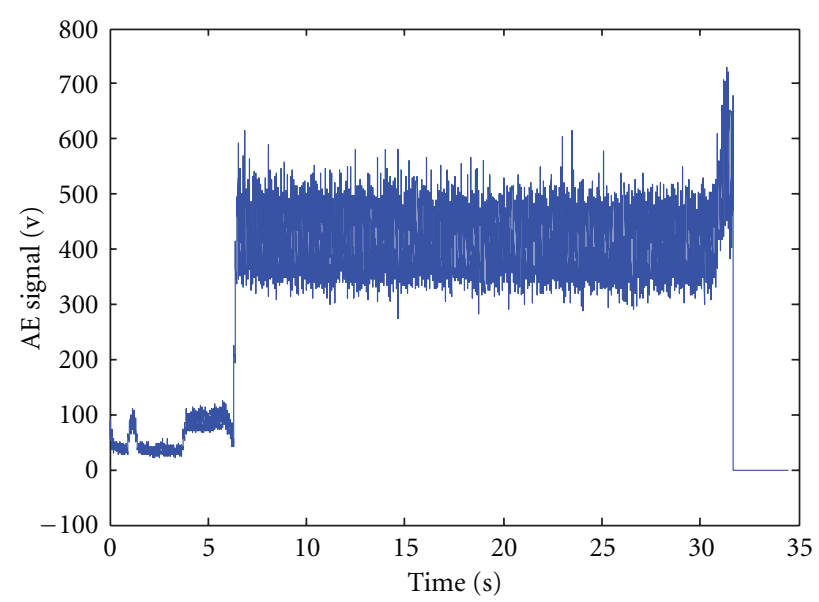

FIgURE 4: AE signal from cutting process.

TABLE 1: Number of rules and parameters of type-1 TSK modeling.

\begin{tabular}{lccccc}
\hline $\begin{array}{l}\text { Cutting section } \\
(\mathrm{mm})\end{array}$ & $0 \sim 10$ & $10 \sim 20$ & $20 \sim 30$ & $30 \sim 40$ & $40 \sim 50$ \\
\hline $\begin{array}{l}\text { Number of data } \\
\text { sets }\end{array}$ & 5500 & 8200 & 5700 & 4500 & 4000 \\
$\begin{array}{l}\text { Number of rules } \\
\begin{array}{l}\text { Standard } \\
\text { deviation }\end{array}\end{array}$ & 24 & 23 & 29 & 34 & 22 \\
\hline
\end{tabular}

the workpiece and gradually reaching the cutting depth. After $30 \mathrm{~s}$, the cutting tool leaves the surface of workpiece. The middle period is the steady cutting period, which contains the most useful information for tool wear condition investigation. In the experiment, five AE signal sets were recorded according to different cutting sections: $0 \sim 10 \mathrm{~mm}$, $10 \sim 20 \mathrm{~mm}, 20 \sim 30 \mathrm{~mm}, 30 \sim 40 \mathrm{~mm}$, and $40 \sim 50 \mathrm{~mm}$. This paper focuses on filtering and capturing the uncertainty on AE signals during the five continuous cutting periods using type-2 TSK fuzzy modeling.

3.2. Data Processing. First, type-1 TSK fuzzy filtering (top part of Figure 3) was used to eliminate noise components in the AE signal. Demirli's extended subtractive clustering identification algorithm [49] was used to estimate both the number and initial location of cluster centers and extract the TSK fuzzy rules from input/output data. The clustering parameters are preinitialized. The cluster radius is confined to the range $[0.15 ; 1.0]$ with a step size of 0.15 . The accept ratio and the reject ratio are both considered in the range $[0$; 1.0 ] with a step size of 0.1 . The squash factor is considered in the range $[0.05 ; 2]$ with a step size of 0.05 . Combined with a least-square estimation algorithm, the fuzzy systems for each cutting length were identified. Table 1 lists the number of rules identified and the standard deviation used for the five AE signal sets. List of cluster centres can be found in [17].

Traditionally, the AE signal is characterized using AE root-mean-square (RMS) measurement in well-controlled tensile tests. To compare AE signal obtained by fuzzy filtering with the one by traditional filter, AE RMS values (illustrated 


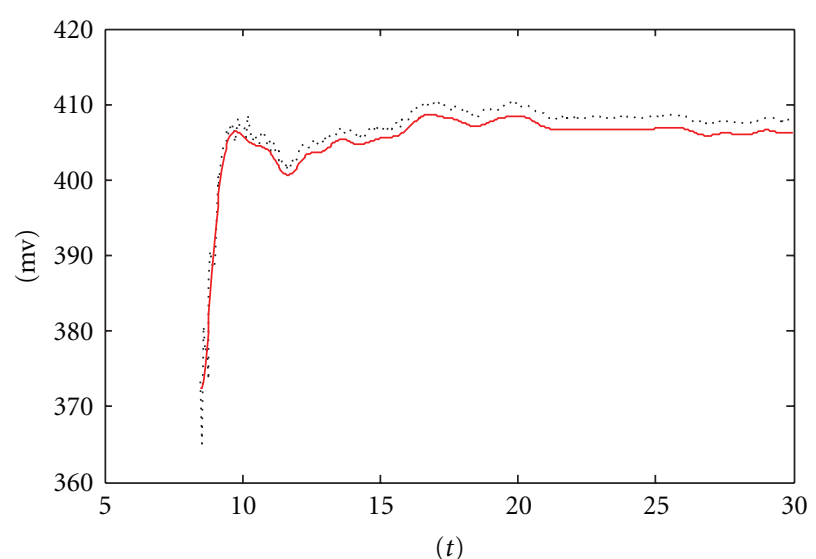

(a) From $0 \mathrm{~mm}$ to $10 \mathrm{~mm}$

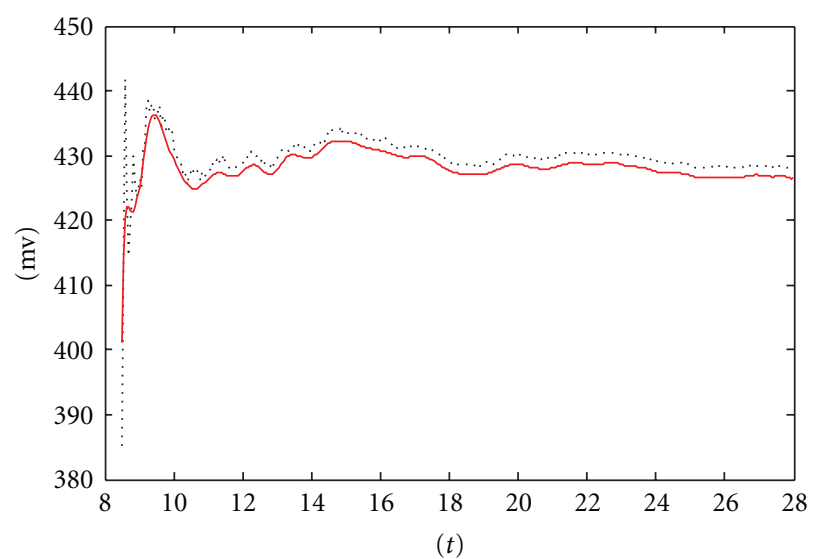

(c) From $20 \mathrm{~mm}$ to $30 \mathrm{~mm}$

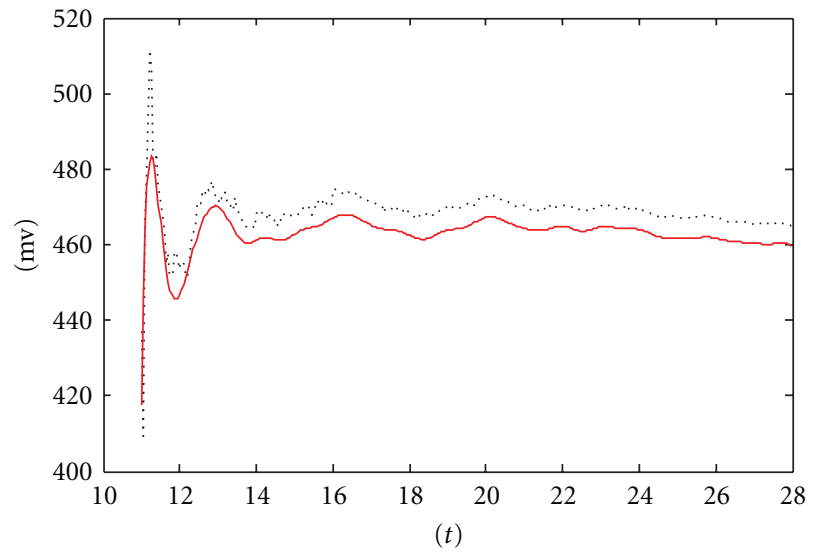

(b) From $10 \mathrm{~mm}$ to $20 \mathrm{~mm}$

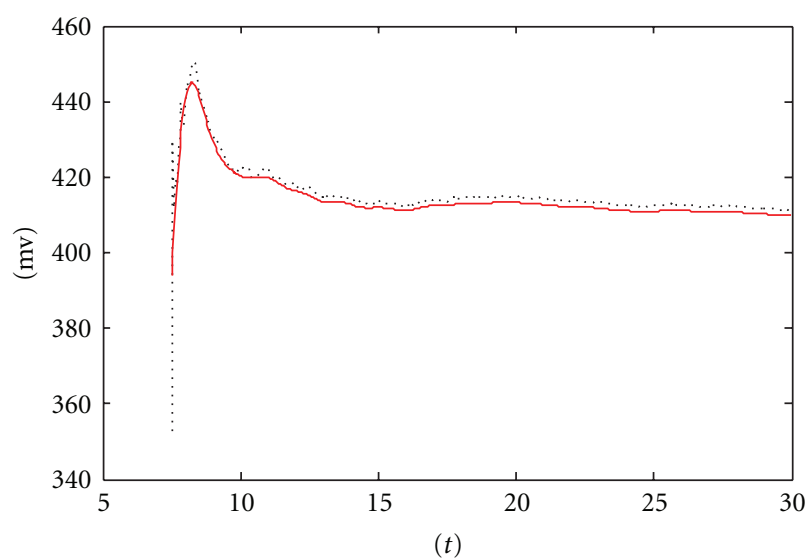

(d) From $30 \mathrm{~mm}$ to $40 \mathrm{~mm}$



$(t)$

...... With traditional filtering

— With fuzzy filtering

(e) From $40 \mathrm{~mm}$ to $50 \mathrm{~mm}$

Figure 5: AE RMS value for different cutting section.

in Figure 5) and $\mathrm{AE}$ mean values (depicted in Figure 6) are calculated for both cases. The dotted curves represent the values obtained by traditional filtering, and the solid ones represent the values obtained by fuzzy filtering. In Figure 5, the dotted curves are above the solid curves. This means that the AE RMS values obtained using the traditional filter are larger than those obtained with fuzzy filtering. The difference could be caused by computation of different algorithm, where fuzzy filtering generates fuzzy rules directly from the input-output data acquired from sensor, without 




(a) From $0 \mathrm{~mm}$ to $10 \mathrm{~mm}$

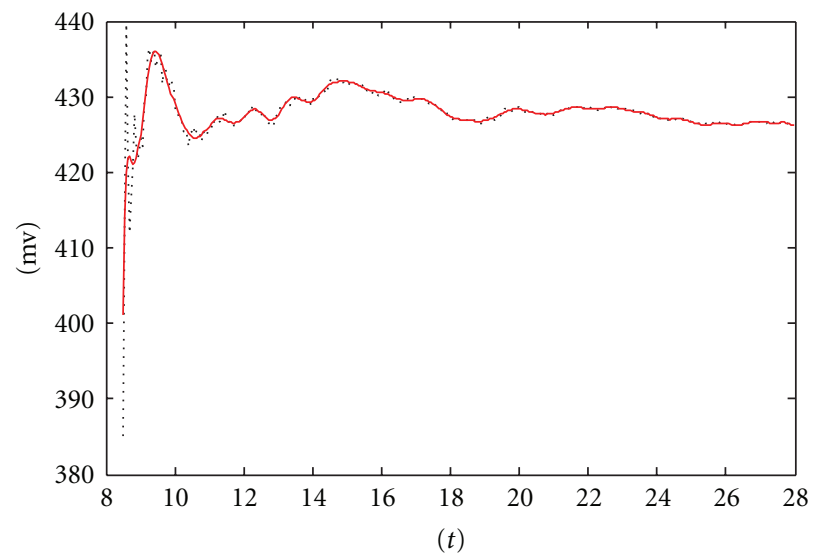

(c) From $20 \mathrm{~mm}$ to $30 \mathrm{~mm}$

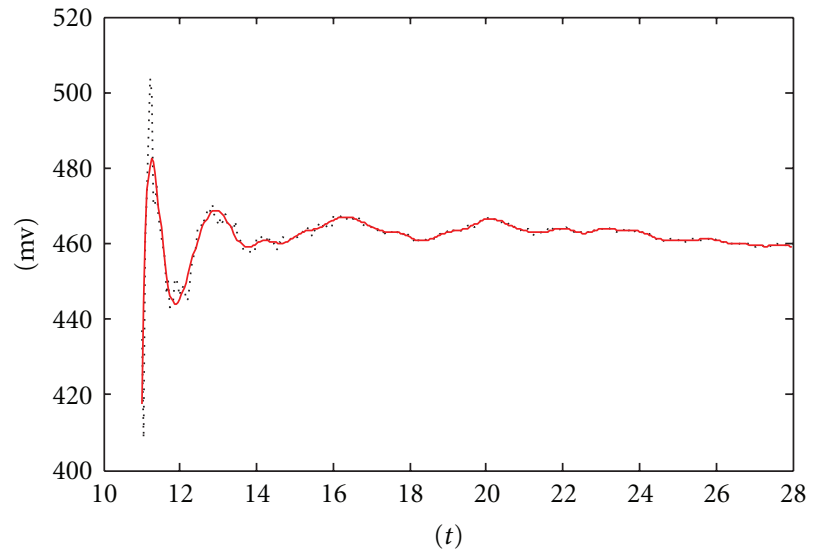

(b) From $10 \mathrm{~mm}$ to $20 \mathrm{~mm}$

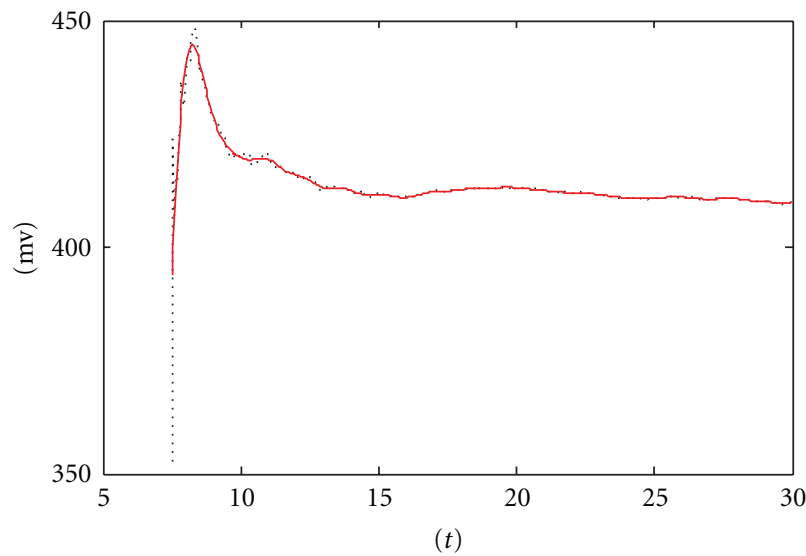

(d) From $30 \mathrm{~mm}$ to $40 \mathrm{~mm}$

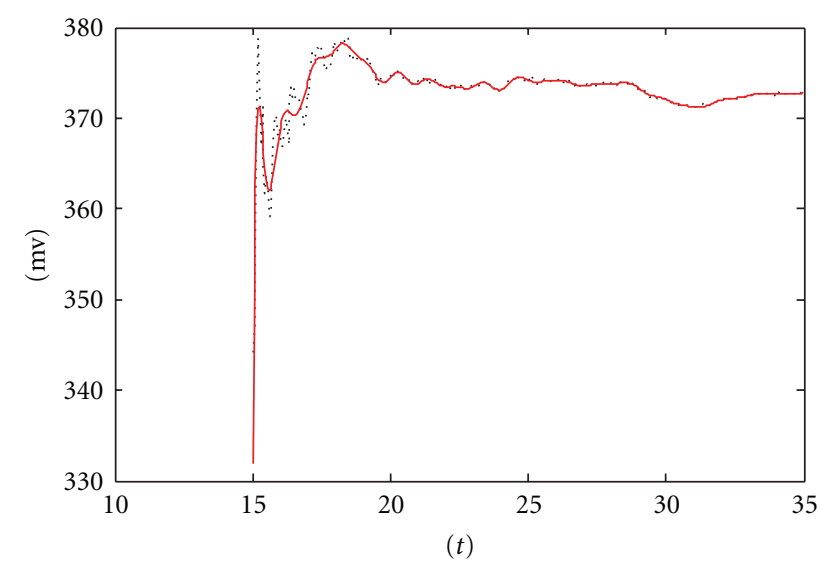

With traditional filtering

_ With fuzzy filtering

(e) From $40 \mathrm{~mm}$ to $50 \mathrm{~mm}$

FIGURE 6: AE mean value for different cutting section.

traditional user-defined high-pass and low-pass filters. The mean values obtained by the two methods are almost same as shown in Figure 6.

The second step consists of expanding the type-1 fuzzy system to a type- 2 system. Because the AE signals used are relatively uncontaminated, uncertainty in the $\mathrm{AE}$ signal is much smaller than the raw AE signal value. The spreading percentage for clusters is confined to the range [0.0\%; $0.01 \%$ ] with a step size of $0.0001 \%$. The spreading percentage for the consequent parameters is considered as $2 \%$. Spreading percentage for clusters and consequent parameters can be found in [17]. The information on uncertainty in the five 
TABLE 2: The variations in modeling results from the five AE signal sets.

\begin{tabular}{|c|c|c|c|c|c|c|c|c|c|}
\hline \multirow{3}{*}{ Cutting section (mm) } & \multicolumn{8}{|c|}{ Variation (mv) } & \multirow{3}{*}{$V B_{B}(\mathrm{~mm}$} \\
\hline & \multicolumn{2}{|c|}{$V_{1}$} & \multicolumn{2}{|c|}{$V_{2}$} & \multicolumn{2}{|c|}{$V_{3}$} & \multicolumn{2}{|c|}{$V_{4}$} & \\
\hline & MAX & MIN & MAX & MIN & MAX & MIN & MAX & MIN & \\
\hline $0 \sim 10$ & 1.1092 & 0.0262 & 1.0257 & 0.0003 & 2.1350 & 0.0108 & 13.6804 & 0.0670 & 0.050 \\
\hline $10 \sim 20$ & 4.7649 & 0.0214 & 4.5361 & 0.0006 & 9.3011 & 0.0018 & 28.7809 & 0.1597 & 0.100 \\
\hline $20 \sim 30$ & 5.9340 & 0.0604 & 5.660 & 0.0155 & 11.5940 & 0.0759 & 92.8960 & 0.1784 & 0.146 \\
\hline $30 \sim 40$ & 4.2204 & 0.0270 & 3.9954 & 0.0007 & 19.3474 & 0.0296 & 117.362 & 0.1980 & 0.196 \\
\hline $40 \sim 50$ & 12.630 & 0.0210 & 12.097 & 0.0001 & 24.7279 & 0.0040 & 128.294 & 0.0464 & 0.373 \\
\hline
\end{tabular}

AE signal sets is shown in Figure 7 between the type- 2 fuzzy output upper boundary $\overline{\mathrm{AE}}$ (dotted curve) and the lower boundary $\mathrm{AE}$ (dashed curve). The overall identified AE signal value $\mathrm{AE}_{\text {fuzzy }}$ is shown as solid curve.

As indicated on Figure 7, there is the uncertainty interval for each cutting section. The most significant is shown on Figure 7(e). Table 2 summarizes the value of maximum and minimum variations between $\overline{\mathrm{AE}}$ and $E_{\mathrm{fuzzy}}, \mathrm{AE}$ and $\mathrm{AE}_{\mathrm{fuzzy}}$, $\overline{\mathrm{AE}}$ and $\mathrm{AE}$, also $\mathrm{AE}_{\text {fuzzy }}$ and the raw $\mathrm{AE}$ signal value $\mathrm{AE}_{\text {raw }}$, where, representatively,

$$
\begin{aligned}
V_{1} & =\left|\overline{\mathrm{AE}}-\mathrm{AE}_{\text {fuzzy }}\right|, \\
V_{2} & =\left|\underline{\mathrm{AE}}-\mathrm{AE}_{\text {fuzzy }}\right|, \\
V_{3} & =|\overline{\mathrm{AE}}-\underline{\mathrm{AE}}|, \\
V_{4} & =\left|\mathrm{AE}_{\text {raw }}-\mathrm{AE}_{\text {fuzzy }}\right| .
\end{aligned}
$$

The greatest variation of each cutting instant is $V_{3}$ between the upper boundary and lower boundary of type-2 interval output. The biggest value is $24.7279 \mathrm{mv}$ in the final cutting section, as same as that on Figure $7(\mathrm{e})$. The last colon on Table 2 lists $V B_{B}$ measured in the end of each cutting section.

As shown in Figures 8 and 9, the development trends of maximum and minimum variations are the same as the tool wear trend. The maximum changes in tool wear condition and $\mathrm{AE}$ signal both occurred during the period when the cutting length was changed from $40 \mathrm{~mm} \sim 50 \mathrm{~mm}$. It is observed that during the initial cutting period (cutting length from $0 \sim 40 \mathrm{~mm}$ ), the variations of AE signal correspond to the initial stages of wear occurring. The period with the most significant variations (cutting section $40 \sim 50 \mathrm{~mm}$ ) corresponds to the period of relatively rapid wear or failure of the cutting tool. Along with the increasing of uncertainty in $\mathrm{AE}$ signal, the development of wear is continuous and monotonically increasing. The sufficient information from $\mathrm{AE}$ uncertainty scheme can be used to make decision or investigate tool condition so as to enhance the reliability of tool wear estimation.

\section{Conclusion}

This paper presented a type-2 fuzzy modelling method to determine $\mathrm{AE}$ in precision machining. The interval output of type-2 fuzzy modelling provides the information of uncertainty in AE estimations. The sufficient information from $\mathrm{AE}$ uncertainty scheme can be used to make decision or investigate tool condition so as to enhance the reliability of tool wear estimation. By applying type-2 fuzzy logic to AE-based tool conditions monitoring, it is possible to automate online diagnosis of cutting tool condition.

Type-2 FLS can model and analyse the uncertainties in machining from the vague information obtained during machining process. The estimation of uncertainties can be used for proving the conformance with specifications for products or autocontrolling of machine system. The application of type-2 fuzzy logic on uncertainty estimation in high precision machining can enable the unmanned use of flexible manufacturing systems and machine tools. It has great meaning for continuous improvement in product quality, reliability, and manufacturing efficiency in machining industry.

\section{Appendices}

\section{A. Subtractive Clustering}

Subtractive clustering identification algorithm [41] is to estimate both the number and initial location of cluster centers and extract the TSK fuzzy rules from input/output data. Subtractive clustering operates by finding the optimal data point to define a cluster centre based on the density of surrounding data points. This method is a fast clustering method designed for high-dimension problems with a moderate number of data points. This is because its computation grows linearly with the data dimension and as the square of the number of data points. A brief description of Chiu's subtractive clustering method is as follows.

Consider a collection of $q$ data points $\left\{x_{1}, x_{2} \ldots, x_{n}\right\}$ specified by $m$-dimensional $x_{j}$. Without loss of generality, assume the feature space is normalized so that all data are bounded by a unit hypercube. Calculate potential for each point by using equation below:

$$
p_{i}=\sum_{j=1}^{q} e^{-\alpha\left\|x_{i}-x_{j} \mid\right\|^{2}}, \quad \alpha=\frac{4}{r_{a}^{2}},
$$

where $\|\cdot\|$ denotes the Euclidean distance. It is noteworthy that only the fuzzy neighbourhood within the radius $r_{a}$ contributes to the measure of potential. 


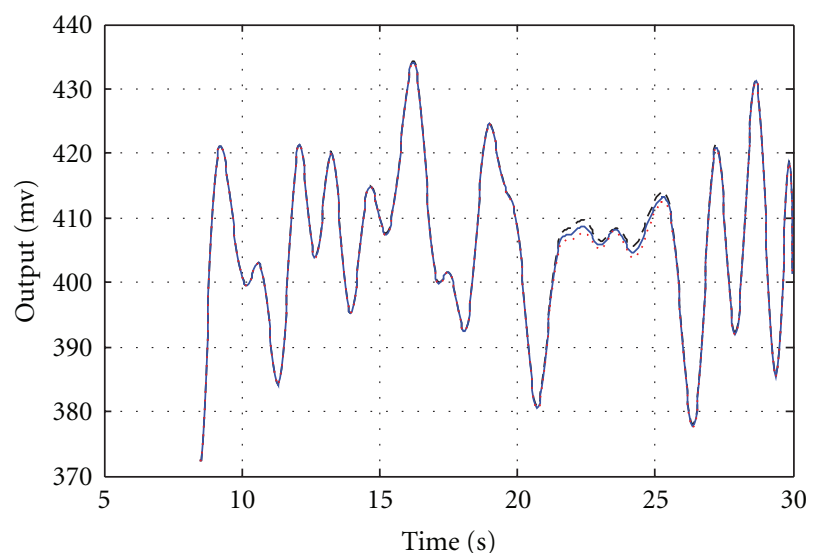

(a) From $0 \mathrm{~mm}$ to $10 \mathrm{~mm}$

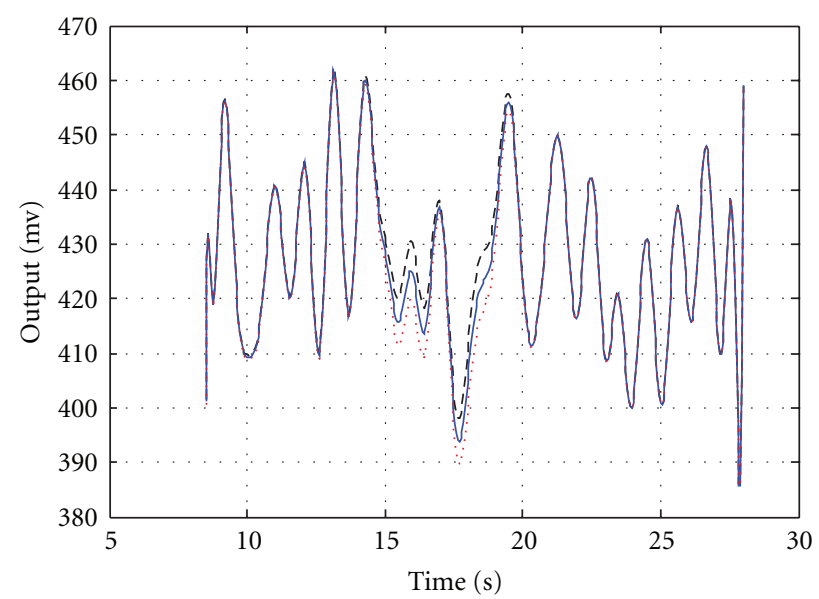

(c) From $20 \mathrm{~mm}$ to $30 \mathrm{~mm}$

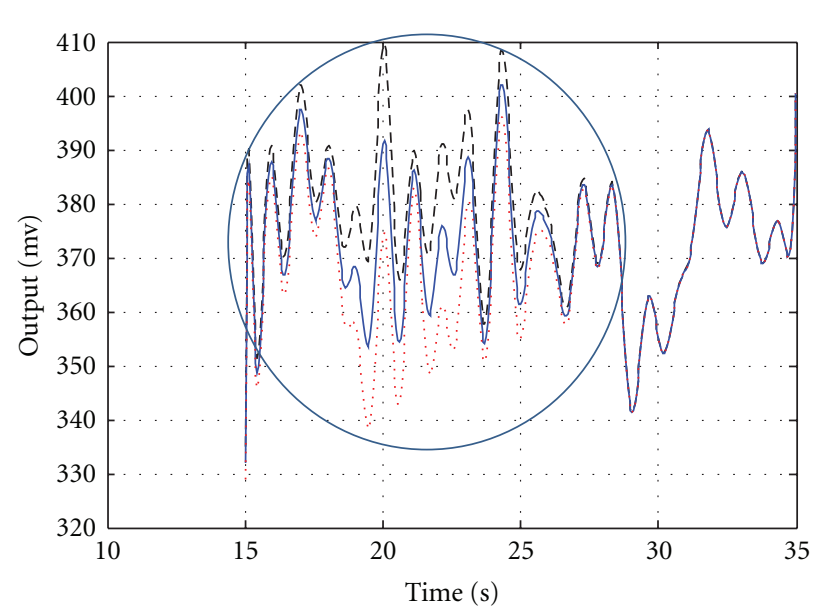

- Average
--- Upper
$\ldots$. Lower

(e) From $40 \mathrm{~mm}$ to $50 \mathrm{~mm}$

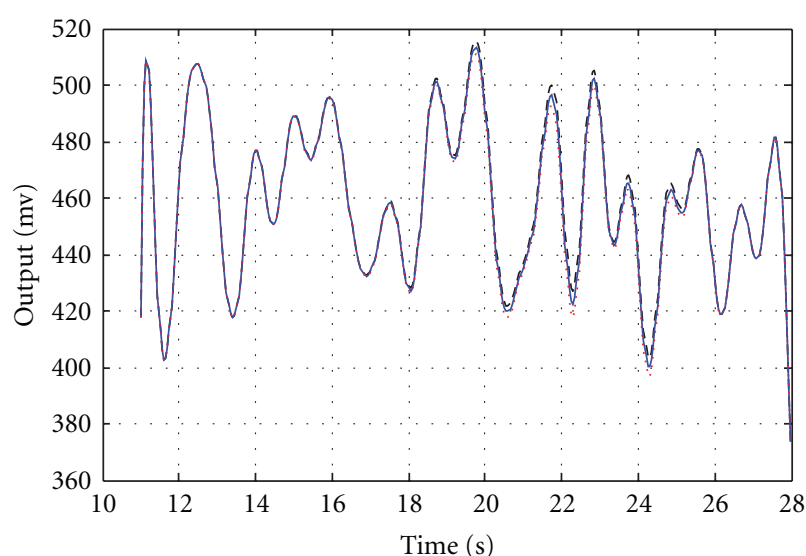

(b) From $10 \mathrm{~mm}$ to $20 \mathrm{~mm}$

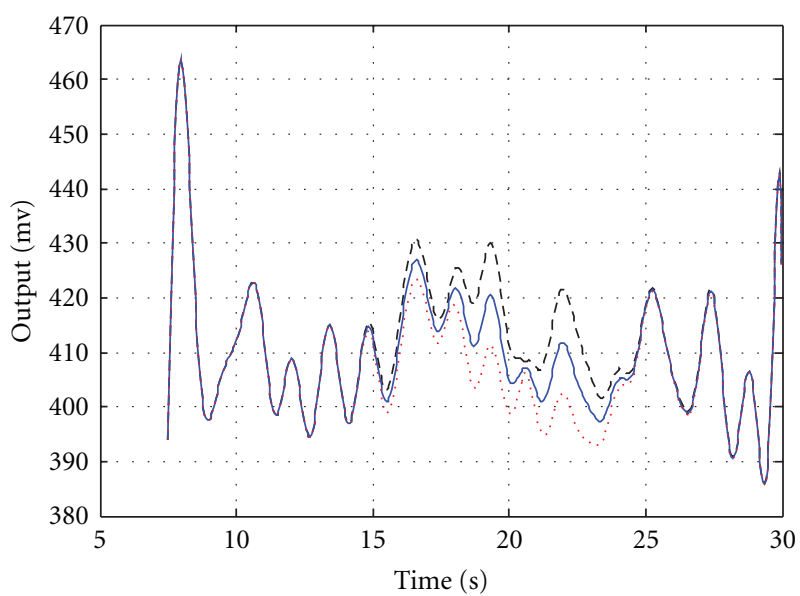

(d) From $30 \mathrm{~mm}$ to $40 \mathrm{~mm}$

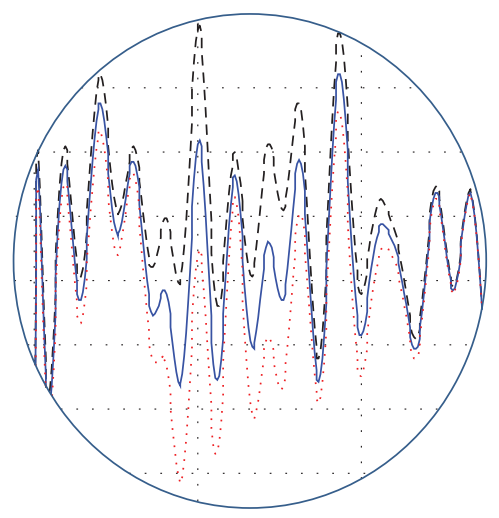

Figure 7: Uncertainties in AE signal in different cutting sections. 


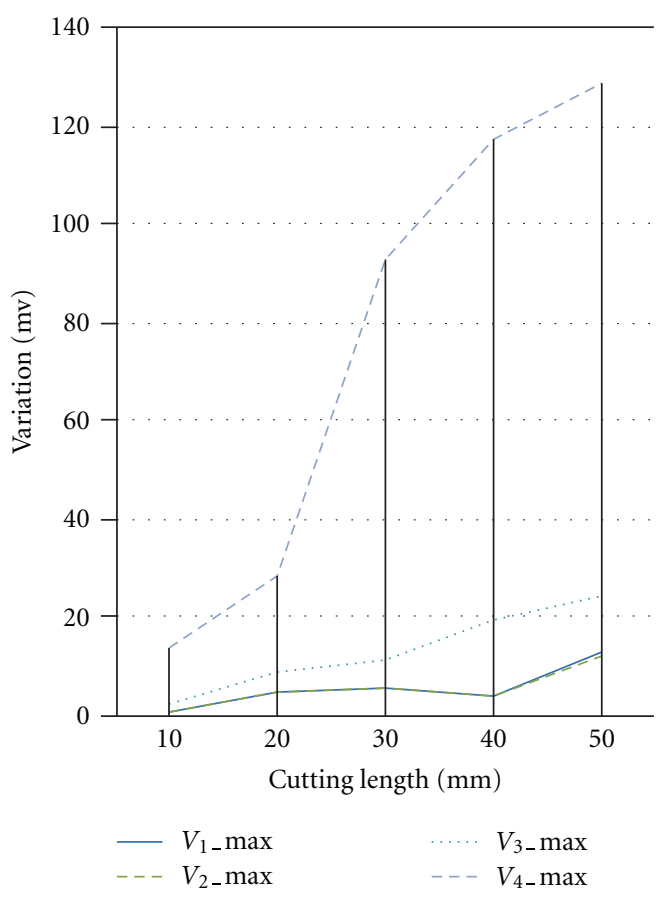

(a) maximum

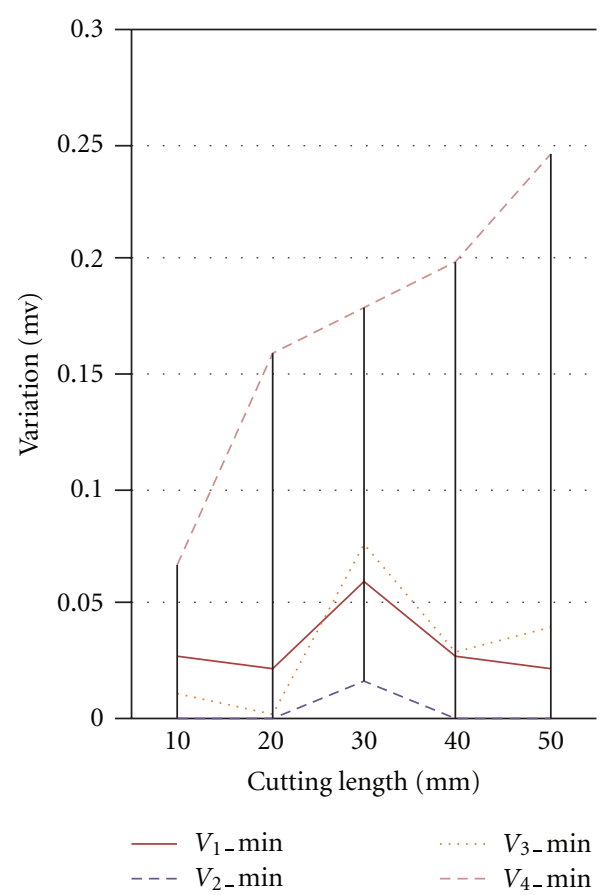

(b) minimum

FIGURE 8: Maximum and minimum variations in different cutting sections.

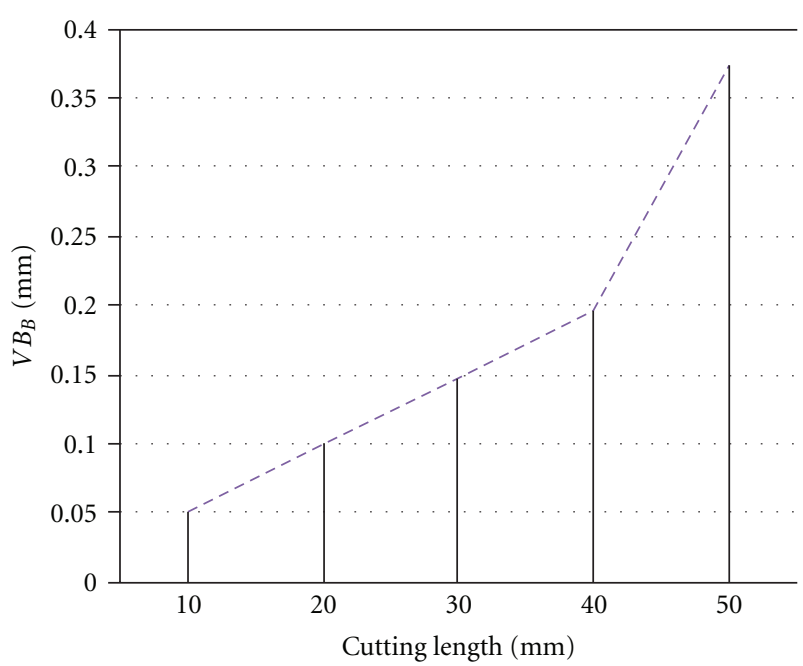

FIGURE 9: Tool wears in different cutting sections.

After the potential of every data point has been computed, the data point with the highest potential is selected as the first cluster center. Assume $x_{1}^{*}$ is the location of the first cluster center, and $p_{1}^{*}$ is its potential value, then revise the potential of each data point $x_{j}$ by the formula

$$
p_{i} \Leftarrow p_{i}-p_{1}^{*} e^{-\beta\left\|x_{i}-x_{1}^{*}\right\|^{2}},
$$

where $\beta=4 / r_{b}^{2}$ and $r_{b}=\eta r_{a}$.

When the potential of all data points have been reduce, by (A.2), the data point with the highest remaining potential is selected as the second cluster center. Then further reduce the potential of each data points. Generally, after $k$ th cluster center has been obtained, the potential of each data point is revised by formula

$$
p_{i} \Longleftarrow p_{i}-p_{k}^{*} e^{-\beta\left\|x_{i}-x_{k}^{*}\right\|^{2}},
$$

where $x_{1}^{*}$ is the location of the $k$ th cluster center and $p_{1}^{*}$ is its potential value.

The process of acquiring new cluster center and revising potential repeats by using the Algorithm 1 .

\section{B. Type-2 TSK Fuzzy Inference Engine}

For the most general structure of T2 TSK FLS-Model I, antecedents are T2 fuzzy sets and consequents are T1 fuzzy sets. Membership grades are interval sets, that is,

$$
\mu_{v}^{k}=\left[\mu_{v}^{k}, \overline{\mu_{v}^{k}}\right]
$$

where $\mu_{v}^{k}$ and $\bar{\mu}_{v}^{k}$ are the lower value and upper value of the $v$ th input variable in the $k$ th rule.

The explicit dependence of the total firing interval for $k$ th rule can be computed as

$$
\begin{aligned}
& f^{k}=\underset{-}{\mu_{1}^{k}}\left(x_{1}\right) \cap \mu_{-}^{k}\left(x_{2}\right) \cap \cdots \cap \overline{-}_{n}^{k}\left(x_{n}\right), \\
& \bar{f}^{k}=\overline{\mu_{1}^{k}}\left(x_{1}\right) \cap \overline{\mu_{2}^{k}}\left(x_{2}\right) \cap \cdots \cap \overline{\mu_{n}^{k}}\left(x_{n}\right),
\end{aligned}
$$




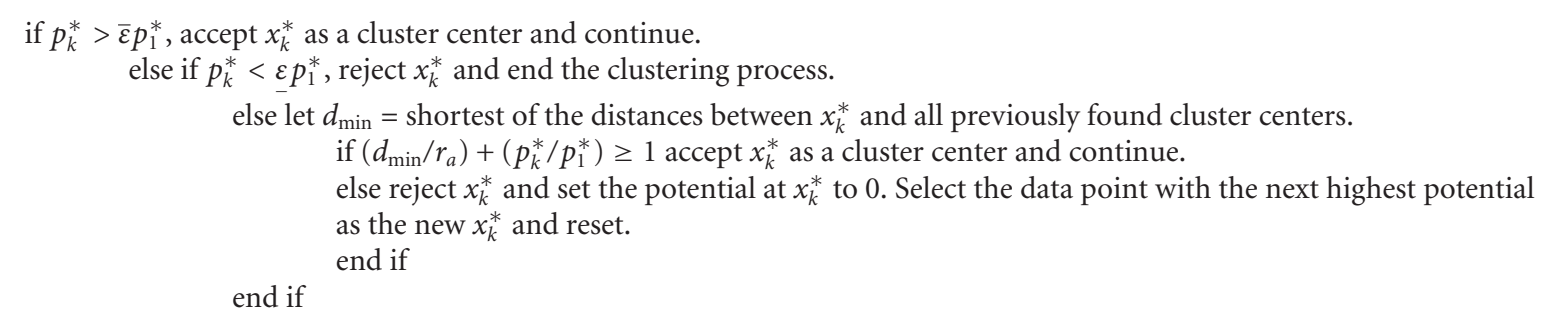

end if

Algorithm 1

where variable $f^{k}$ and $\bar{f}^{k}$ denote lower value and upper value of fire strength. The symbol $\cap$ is a conjunction operator, which is a T-norm. It can be either MIN operator $\wedge$ or product operator $*$.

The interval value of the consequent of the $k$ th rule $w^{k}$ is $w^{k}=\left[w_{l}^{k}, w_{r}^{k}\right]$, where

$$
\begin{aligned}
& w_{l}^{k}=\sum_{j=1}^{n} c_{j}^{k} x_{j}+c_{0}^{k}-\sum_{j=1}^{n} s_{j}^{k}\left|x_{j}\right|-s_{0}^{k}, \\
& w_{l}^{k}=\sum_{j=1}^{n} c_{j}^{k} x_{j}+c_{0}^{k}+\sum_{j=1}^{n} s_{j}^{k}\left|x_{j}\right|-s_{0}^{k} .
\end{aligned}
$$

Here $w_{l}^{k}$ and $w_{r}^{k}$ denote lower and upper values of consequent output for $k$ th rule. $c_{j}^{k}$ and $s_{j}^{k}$ denote the centre (mean) and the spread of fuzzy number $\tilde{p}_{\dot{j}}^{k}$.

So, the extended output of the IT2 TSK FLS can be calculated by using following equation:

$$
\begin{aligned}
\tilde{w}= & {\left[w_{l}, w_{r}\right] } \\
= & \int_{w^{1} \in\left[w_{l}^{1}, w_{r}^{1}\right]} \cdots \int_{w^{n} \in\left[w_{l}^{n}, w_{r}^{n}\right]} \\
& \times \int_{f^{1} \in\left[f_{-}^{1}, f^{1}\right]} \cdots \int_{f^{M} \in\left[f_{-}^{M}, f^{M}\right]} \frac{1}{\sum_{k=1}^{M} f^{k} w^{k} / \sum_{k=1}^{M} f^{k}} .
\end{aligned}
$$

Hence $\widetilde{w}=\left[w_{l}, w_{r}\right]$ is an interval type- 1 set, the two endpoints $w_{l}$ and $w_{r}$ can be obtained by using equations below:

$$
w_{l}=\frac{\sum_{k=1}^{n} f_{l}^{k} w_{l}^{k}}{\sum_{k=1}^{n} f_{l}^{k}}, \quad w_{r}=\frac{\sum_{k=1}^{n} f_{r}^{k} w_{r}^{k}}{\sum_{k=1}^{n} f_{r}^{k}} .
$$

This interval set of the output has the information about the uncertainties that are associated with the crisp output, and this information can only be obtained by working with T2 TSK FLS. To compute $\tilde{w}$, two endpoints $w_{l}$ and $w_{r}$ must be computed. In order to compute $w_{l}$ and $w_{r}, f_{l}^{k}$ and $f_{r}^{k}$ have to be determined. $w_{l}$ and $w_{r}$ can be obtained by using the iterative procedure KM Algorithm [30]. Here, the computation procedure for $w_{l}$ and $w_{r}$ is briefly provided as follows:
Without loss of generality, assume that the precomputed $w_{r}^{k}$ are arranged in ascending order: $w_{r}^{1} \leq w_{r}^{2} \leq \cdots \leq w_{r}^{m}$, then, we have the following.

Step 1. Compute $w_{r}$ in (B.6) by initially setting

$$
f_{r}^{k}=\frac{\left(f^{k}+\bar{f}^{k}\right)}{2}
$$

for $k=1, \ldots, R$, where $f^{k}$ and $\bar{f}^{k}$ have been previously computed using (B.2) and (B.3), respectively, and let $w_{r}^{\prime} \equiv$ $w_{r}$.

Step 2. Find $y(1 \leq y \leq m-1)$ such that $w_{r}^{y} \leq w_{r}^{\prime} \leq w_{r}^{y+1}$.

Step 3. Compute $w_{r}$ in with $f_{r}^{k}=f^{k}$ for $k \leq y$ and $f_{r}^{k}=\bar{f}^{k}$ for $k>y$, and let $w_{r}^{\prime \prime} \equiv w_{r}$.

Step 4. If $w_{r}^{\prime \prime} \neq w_{r}^{\prime}$, then go to Step 5. If $w_{r}^{\prime \prime}=w_{r}^{\prime}$, then stop. And set $w_{r}^{\prime \prime} \equiv w_{r}$.

Step 5. Set $w_{r}^{\prime}=w_{r}^{\prime \prime}$ and return to Step 2 .

The procedure for computing $w_{l}$ is very similar to the one just given for $w_{r}$. Replace $w_{r}^{k}$ by $w_{l}^{k}$, and compute $w_{l}$. In Step 2 find $z(1 \leq z \leq m-1)$ such that $w_{l}^{z} \leq w_{l}^{\prime} \leq w_{l}^{z+1}$. Additionally, in Step 3 compute $w_{l}$ with $f_{r}^{k}=f^{k}$ for $k \leq z$ and $f_{r}^{k}=\bar{f}^{k}$ for $k>z$.

In an interval type- 2 TSK FLS, output $\widetilde{w}$ is an interval type-1 fuzzy set, so the crisp output of any interval type- 2 TSK FLS can be obtained by using the average value of $w_{l}$ and $w_{r}$, that is,

$$
w^{*}=\frac{w_{l}+w_{r}}{2}
$$

\section{References}

[1] L. H. Wang and R. X. Gao, Condition Monitoring and Control for Intelligent Manufacturing, Springer Series in Advanced Manufacturing, Springer, New York, NY, USA, 2006, ISBN: 978-1-84628-268-3. 
[2] K. Iwata and T. Moriwaki, "Application of acoustic emission measurement to in-process sensing of tool wear," Annals of the CIRP, vol. 26, no. 1-2, pp. 19-23, 1977.

[3] S. Y. Liang and D. A. Dornfeld, "Tool wear detection using time series analysis of acoustic emission," Journal of Engineering for Industry, vol. 111, no. 3, pp. 199-205, 1989.

[4] H. V. Ravindra, Y. G. Srinivasa, and R. Krishnamurthy, "Acoustic emission for tool condition monitoring in metal cutting," Wear, vol. 212, no. 1, pp. 78-84, 1997.

[5] E. Emel and E. Kannatey-Asibu, "Tool failure monitoring in turning by pattern recognition analysis of AE signals," Journal of Engineering for Industry, vol. 110, no. 2, pp. 137-145, 1988.

[6] X. Li and Z. Yuan, "Tool wear monitoring with wavelet packet transform-fuzzy clustering method," Wear, vol. 219, no. 2, pp. 145-154, 1998.

[7] A. K. Menon and Z. E. Boutaghou, "Time-frequency analysis of tribological systems-Part I: implementation and interpretation," Tribology International, vol. 31, no. 9, pp. 501-510, 1998.

[8] C. Heil and D. Walnut, "Continuous and discrete wavelet transforms," SIAM Review, vol. 31, no. 4, pp. 628-666, 1989.

[9] E. P. Serrano and M. A. Fabio, "Application of the wavelet transform to acoustic emission signals processing," IEEE Transactions on Signal Processing, vol. 44, no. 5, pp. 1270-1275, 1996.

[10] S. V. Kamarthi, S. R. T. Kumara, and P. H. Cohen, "Wavelet representation of acoustic emission in turning process," Intelligent Engineering Systems Through Artificial Neural Networks, vol. 5, pp. 861-866, 1995.

[11] X. Li, "Real-time detection of the breakage of small diameter drills with wavelet transform," International Journal of Advanced Manufacturing Technology, vol. 14, no. 8, pp. 539$543,1998$.

[12] I Nur Tansel, C. Mekdeci, and C. Mclaughlin, "Detection of tool failure in end milling with wavelet transformations and neural networks (WT-NN)," International Journal of Machine Tools and Manufacture, vol. 35, no. 8, pp. 1137-1147, 1995.

[13] N. Kasashima, K. Mori, G. H. Ruiz, and N. Taniguchi, "Online failure detection in face milling using discrete wavelet transform," CIRP Annals-Manufacturing Technology, vol. 44, no. 1, pp. 483-487, 1995.

[14] X. Li, "A brief review: acoustic emission method for tool wear monitoring during turning," International Journal of Machine Tools and Manufacture, vol. 42, no. 2, pp. 157-165, 2002.

[15] S. Darenfed and S. M. Wu, "Polynomial learning networks for cutting tool diagnosis in machining operations," Transactions of the Canadian Society for Mechanical Engineering, vol. 16, no. 2, pp. 147-163, 1992.

[16] Y. Quan, M. Zhou, and Z. Luo, "On-line robust identification of tool-wear via multi-sensor neural-network fusion," Engineering Applications of Artificial Intelligence, vol. 11, no. 6, pp. 717-722, 1998.

[17] Q. Ren, L. Baron, and M. Balazinski, "Fuzzy identification of cutting acoustic emission with extended subtractive cluster analysis," Nonlinear Dynamics, inpress.

[18] X. Li, Y. Yao, and Z. Yuan, "On-line tool condition monitoring system with wavelet fuzzy neural network," Journal of Intelligent Manufacturing, vol. 8, no. 4, pp. 271-276, 1997.

[19] R. J. Kuo and P. H. Cohen, "Intelligent tool wear estimation system through artificial neural networks and fuzzy modeling," Artificial Intelligence in Engineering, vol. 12, no. 3, pp. 229-242, 1998.

[20] P. Lezanski, "Intelligent system for grinding wheel condition monitoring," Journal of Materials Processing Technology, vol. 109, no. 3, pp. 258-263, 2001.
[21] J. Sun, M. Rahman, Y. S. Wong, and G. S. Hong, "Multiclassification of tool wear with support vector machine by manufacturing loss consideration," International Journal of Machine Tools and Manufacture, vol. 44, no. 11, pp. 11791187, 2004.

[22] I. Deiab, K. Assaleh, and F. Hammad, "On modeling of tool wear using sensor fusion and polynomial classifiers," Mechanical Systems and Signal Processing, vol. 23, no. 5, pp. 1719-1729, 2009.

[23] L. A. Zadeh, "Fuzzy sets," Information and Control, vol. 8, no. 3, pp. 338-353, 1965.

[24] T. Takagi and M. Sugeno, "Fuzzy identification of systems and its applications to modeling and control," IEEE Transactions on Systems, Man and Cybernetics, vol. 15, no. 1, pp. 116-132, 1985.

[25] M. Sugeno and G. T. Kang, "Structure identification of fuzzy model," Fuzzy Sets and Systems, vol. 28, no. 1, pp. 15-33, 1988.

[26] T. A. Johansen and B. A. Foss, "Identification of non-linear system structure and parameters using regime decomposition," Automatica, vol. 31, no. 2, pp. 321-326, 1995.

[27] D. Füssel, P. Ballé, and R. Isermann, "Closed loop fault diagnosis based on a nonlinear process model and automatic fuzzy rule generation," in Proceedings of the 4th Fault Detection, Supervision and Safety of Technical Processes, 1997.

[28] L. A. Zadeh, "The concept of a linguistic variable and its application to approximate reasoning-I," Information Sciences, vol. 8, no. 3, pp. 199-249, 1975.

[29] M. Mizumoto and K. Tanaka, "Fuzzy sets and type 2 under algebraic product and algebraic sum," Fuzzy Sets and Systems, vol. 5, no. 3, pp. 277-290, 1981.

[30] N. N. Karnik and J. M. Mendel, "Introduction to Type-2 fuzzy logic systems," Technical report, University of Southern California, 1998, http://sipi.usc.edu/-Mendel/report .

[31] R. John, "Type 2 fuzzy sets: an appraisal of theory and applications," International Journal of Uncertainty, Fuzziness and Knowlege-Based Systems, vol. 6, no. 6, pp. 563-576, 1998.

[32] L. A. Zadeh, "Fuzzy logic = computing with words," IEEE Transactions on Fuzzy Systems, vol. 4, no. 2, pp. 103-111, 1996.

[33] L. A. Zadeh, "From computing with numbers to computing with words-From manipulation of measurements to manipulation of perceptions," IEEE Transactions on Circuits and Systems, vol. 46, no. 1, pp. 105-119, 1999.

[34] J. M. Mendel, Uncertain Rule-Based Fuzzy logic SystemsIntroduction on New Directions, Prentice hall PTR, Upper saddle river, NJ, USA, 2001.

[35] H. Hagras, "Type-2 FLCs: a new generation of fuzzy controllers," IEEE Computational Intelligence Magazine, vol. 2, no. 1, pp. 30-43, 2007.

[36] D. Wu and W. W. Tan, "A simplified type-2 fuzzy logic controller for real-time control," ISA Transactions, vol. 45, no. 4, pp. 503-516, 2006.

[37] Q. Liang and J. M. Mendel, "Introduction to type-2 TSK fuzzy logic systems," in Proceedings of the IEEE International Fuzzy Systems Conference (FUZZ-IEEE '99), Seoul, Korea, August 1999.

[38] J. M. Mendel, H. Hagras, and R. I. John, "Standard background material about interval type-2 fuzzy logic systems that can be used by all authors," http://ieee-cis.org/_files/standards.t2.win.pdf .

[39] J. M. Mendel, "Advances in type-2 fuzzy sets and systems," Information Sciences, vol. 177, no. 1, pp. 84-110, 2007.

[40] R. Qun, L. Baron, and M. Balazinski, "Type-2 takagi-sugenokang fuzzy logic modeling using subtractive clustering," in Proceedings of the 25th Annual Meeting of the North American 
Fuzzy Information Processing Society (NAFIPS '06), pp. 120125, Montreal, Canada, June 2006.

[41] S. L. Chiu, "Fuzzy model identification based on cluster estimation," Journal of Intelligent and Fuzzy Systems, vol. 2, pp. 267-278, 1994.

[42] Q. Ren, L. Baron, K. Jemelniak, and M. Balazinski, “Tool condition monitoring using the TSK fuzzy approach based on subtractive custering method," in News Frontiers in Applied Artificial Intelligence, pp. 52-61, Springer, Berlin, Germany, 2008.

[43] Q. Ren, M. Balazinski, L. Baron, and K. Jemielniak, “TSK fuzzy modeling for tool wear condition in turning processes: an experimental study," Engineering Applications of Artificial Intelligence, vol. 24, no. 2, pp. 260-265, 2011.

[44] Q. Ren, L. Baron, K. Jemelniak, and M. Balazinski, "Acoustic emission signal feature analysis using Type-2 fuzzy logic system," in Proceedings of the 29th North American Fuzzy Information Processing Society Annual Conference (NAFIPS '10), pp. 1-6, Toronto, Canada, July 2010.

[45] Q. Ren, M. Balazinski, and L. Baron, "Uncertainty prediction for tool wear condition using type-2 TSK fuzzy approach," in Proceedings of the IEEE International Conference on Systems, Man and Cybernetics (SMC '09), pp. 660-665, San Antonio, Tex, USA, October 2009.

[46] Q. Ren, L. Baron, and M. Balazinski, "Application of type-2 fuzzy estimation on uncertainty in machining: an approach on acoustic emission during turning process," in Proceedings of the 28th Annual Meeting of the North American Fuzzy Information Processing Society (NAFIPS '09), Cincinnati, Ohio, USA, June 2009.

[47] Q. Ren, L. Baron, K. Jemelniak, and M. Balazinski, "Modelling of dynamic micromilling cutting forces using Type-2 fuzzy rule-based system," in Proceedings of the IEEE World Congress on Computational Intelligence International Conference on Fuzzy Systems (WCCI '10), pp. 2311-2317, Barcelona, Spain, 2010.

[48] Q. Ren, M. Balazinski, and L. Baron, “Type-2 TSK fuzzy logic system and its type-1 counterpart," International Journal of Computer Applications, vol. 20, no. 6, pp. 8-13, 2011.

[49] K. Demirli, S. X. Cheng, and P. Muthukumaran, "Subtractive clustering based modeling of job sequencing with parametric search," Fuzzy Sets and Systems, vol. 137, no. 2, pp. 235-270, 2003. 

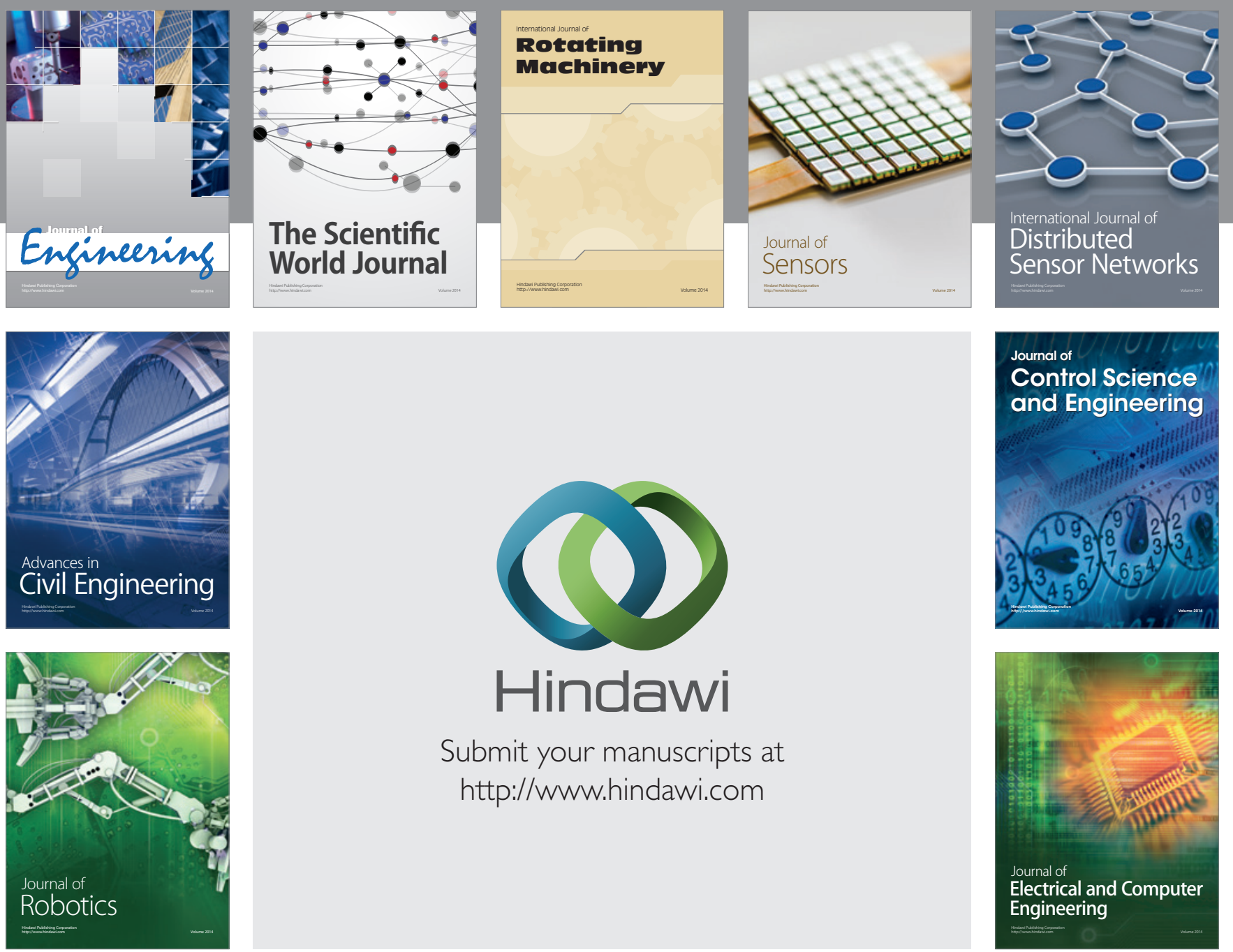

Submit your manuscripts at

http://www.hindawi.com
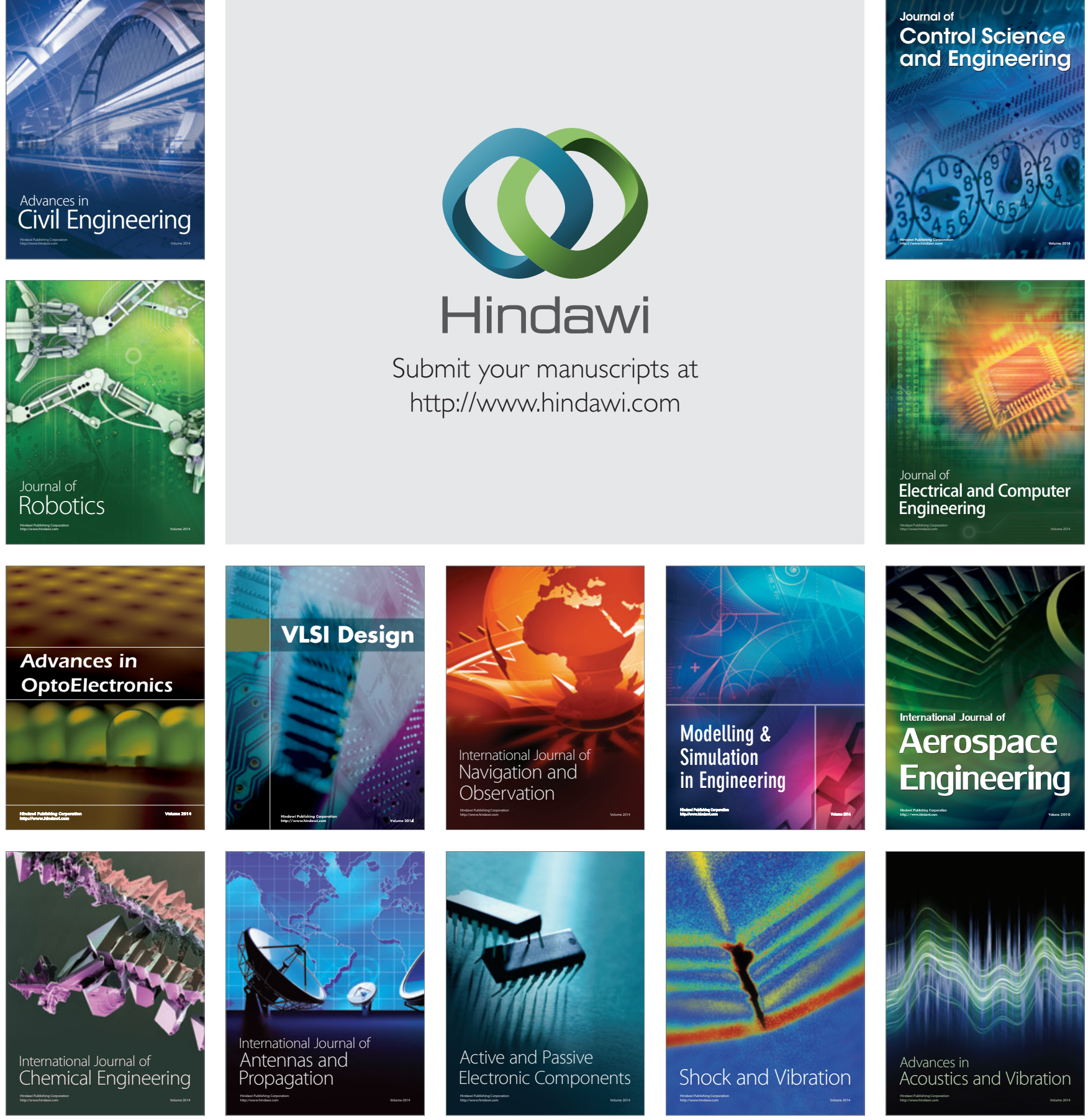